\title{
Decisões de financiamento bancário por parte da banca angolana: o caso do Banco de Poupança e Crédito
}

\author{
Bank financing decisions by Angolan banks: the case of Banco de Poupança e Crédito
}

Benedito Manuel ${ }^{1}$; Fernando Oliveira Tavares ${ }^{2}$; Luís Pacheco ${ }^{3}$.

\author{
${ }^{1}$ E-mail: benedito manuel@hotmail.com \\ FE - Universidade Katyavala Bwila \\ (Benguela) \\ ${ }^{2}$ E-mail: ftavares@upt.pt \\ Universidade Portucalense \\ ${ }^{3}$ E-mail: luisp@upt.pt \\ Universidade Portucalense
}

Resumo: Este trabalho tem como objetivo realizar um estudo sobre as ferramentas e técnicas usadas pelo Banco de Poupança e Crédito na análise e avaliação de projetos de investimento dos seus mutuários. Para a prossecução deste objetivo fez-se a comparação dos seus processos de decisão em relação aos apresentados na literatura científica, de modo a compreender a problemática do risco de crédito e do crédito malparado do banco. A investigação conclui que por se tratar de um banco público, este vê-se forçado a apoiar projetos que de outra forma não seriam aceites. Também se verificou que uma parte do crédito em incumprimento do banco tem origem em clientes alancados por serviços prestados ao Estado, faltando ao banco exigir as devidas garantias reais ou a aplicação de seguros de crédito. Conclui-se que o problema do banco identifica-se com os decorrentes da informação assimétrica, nomeadamente a seleção adversa e o risco moral.

Palavras-chave: Análise de Investimentos; Métodos de Análise e Avaliação de Projetos de Investimento; Sistema Financeiro Angolano; Banco de Poupança e Crédito.

Abstract: This paper aims to carry out a study about the tools and techniques used by the Savings and Credit Bank in the analysis and evaluation of investment projects of its borrowers. In order to achieve this objective, a comparison between its decision-making processes and the ones presented in the scientific literature was carried out, to be able to understand the problem of credit risk and bad credit standing of the bank. The investigation concludes that because it is a public bank, it is forced to support projects that would otherwise not be accepted. It has also been found that a portion of the credit in default of the bank originates in clients liable for services rendered to the State, lacking the bank to demand the proper guarantees or the application of credit insurance. It is concluded that the bank problem relates to those arising from asymmetric information, namely adverse selection and moral risk.

Keywords: Analysis of Investments; Methods of Analysis and Evaluation of Investment Projects; Angolan Financial System; Banco de Poupança e Crédito 


\section{pontěditora}

\section{Introdução}

Um investimento é uma aplicação de fundos escassos que geram rendimentos durante certo tempo, de forma a maximizar a riqueza da empresa. Segundo Barros (2007), o projeto de investimento é um conceito entendido em duas vertentes: enquanto plano (intenção) de investimento e enquanto estudo (processo escrito) da intenção do investimento (negócio).

Perante a intenção de investimento, considera-se que as duas vertentes são equivalentes, sendo reunidas num dossiê do projeto de investimento. Segundo Marques (1998), enquanto plano de investimento o projeto é uma proposta de aplicação de recursos escassos que possuem aplicações alternativas a um negócio, do qual se espera gerar rendimentos futuros durante determinado tempo, capazes de remunerar a aplicação de recursos.

O objetivo deste trabalho é realizar um estudo sobre as ferramentas e técnicas que o Banco de Poupança e Crédito (BPC) aplica na análise e avaliação de projetos de investimento dos seus mutuários, mediante a comparação dos seus processos com os apresentados na literatura científica, com vista a uma melhor forma de lidar com o risco de crédito e a problemática do crédito mal parado.

Num ambiente ainda de grande fragilidade económica, nascia a 24 de janeiro de 1956 o Banco Comercial de Angola (BCA), com um capital social detido em 50\% pelo Banco Português do Atlântico, enquanto a parte restante era repartida por outros fundadores, entre os quais Cupertino de Miranda, que presidia ao seu Conselho de Administração e Manuel Vinhas, do Grupo Cuca (BPC, 2011). A criação daquele banco tinha como fundamento a realização de operações bancárias que, de acordo com os seus Estatutos, concentrar-se-iam no crédito agrícola e industrial. No entanto, ao longo dos anos, o Banco assumiu distintas denominações de acordo com as diferentes fases da evolução do sistema financeiro angolano.

A mudança da situação política em Portugal, em 1974, e o alcançar da independência nacional levaram as autoridades angolanas a intervir para evitar o desmoronamento de todo o sistema monetário e financeiro, através da célebre operação desencadeada a 14 de agosto de 1976, que ficou conhecida como a "Tomada da Banca". Foram confiscados os ativos e passivos do Banco de Angola e criado o Banco Nacional de Angola (BNA), através da Lei n. ${ }^{o}$ 69/76 de 5 de novembro, e a Lei n. ${ }^{\text { }}$ 70/76 criou o Banco Popular de 


\section{pontěditora}

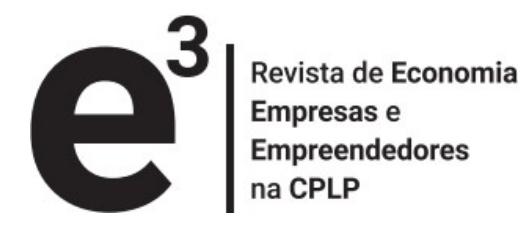

Angola. A partir de 1991, o Governo iniciou a implementação da reforma do setor financeiro e aprovou a legislação que criou um sistema bancário de dois níveis, nomeadamente através da Lei n. ${ }^{\circ}$ 4/91 - Lei Orgânica do Banco Nacional de Angola - e da Lei n. ${ }^{\circ}$ 5/91 - Lei das Instituições Financeiras, que dava fim ao monopólio do Estado no setor financeiro.

A nova Lei Orgânica do BNA considera-o como Banco Central de um sistema bancário de dois níveis, consagrado como autoridade monetária, agente de autoridade cambial e separado das funções comerciais, enquanto a Lei das Instituições Financeiras veio regular o exercício de funções de crédito e a constituição de outras instituições de capitais privados, nacionais ou estrangeiras.

O antigo Banco Popular de Angola passou a Banco de Poupança e Crédito (BPC) através do Decreto n. ${ }^{\circ} 47 / 91$, tendo como únicos acionistas o Estado e o Instituto Nacional de Segurança Social. O sistema bancário nacional passou então a ser composto, para além do BNA, por mais dois bancos comerciais constituídos sob forma de sociedades anónimas de capitais públicos - o Banco de Poupança e Crédito (BPC) e o Banco de Comércio e Indústria (BCI).

Atualmente, o BPC é um dos maiores bancos comerciais do país, com uma rede de 406 balcões, espalhada por todo o território nacional e um número significativo de colaboradores. O Banco oferece uma gama variada de produtos e serviços, de forma responsável, a clientes institucionais, empresas e particulares e assume-se como parceiro social do Estado nos programas de aumento da capacidade produtiva nacional, de regulação da vida económica e da melhoria da qualidade de vida das populações.

Como Banco de referência em Angola, a sua estratégia está sustentada por três elementos fundamentais: melhoramento contínuo dos serviços oferecidos; apoio das iniciativas públicas e privadas no domínio de investimento, sempre respeitando e compreendendo as necessidades dos clientes; desenvolvimento do sistema de informação, com uma excelente rede de balcões em todo o país.

O presente artigo está estruturado do seguinte modo: a secção seguinte descreve brevemente os principais riscos decorrentes da concessão de crédito por parte da banca e as técnicas de análise de risco. A terceira secção apresenta a metodologia do BPC relativamente aos processos de concessão de crédito, bem como caracteriza a situação atual do banco. Por último, são discutidas as conclusões e apresentadas algumas

$\mathrm{e}^{3}$ - Revista de Economia, Empresas e Empreendedores na CPLP | Volume 4 | Número 1 
limitações do estudo.

\section{Revisão da literatura}

A relevância da análise de investimentos constitui o principal sustentáculo de decisões que condicionam de forma marcante a composição do ativo fixo e a estrutura de funcionamento de uma dada organização no médio e longo prazo (Souza e Neto, 2012). Segundo Soares et al. (2007), o projeto de investimento é composto pela sua descrição física (layout de unidades de produção ou de operação), considerações de natureza mercadológica, cronograma de implantação do empreendimento, descrição das fontes de financiamento, além dos seguintes dados: investimentos permanentes (imóveis, máquinas, instalações, etc.); investimento em capital para fundo de maneio (stocks, matérias-primas, subsidiárias, etc.); valor de venda ao longo do período de análise do projeto e valor dos gastos ao longo do período de análise do projeto. Para Albino, Tavares e Pacheco (2016) o projeto de investimento pressupõe uma sequência de estudos que visam verificar a sua viabilidade económico-financeira.

Em suma, o projeto de investimento, segundo Patah e Carvalho (2016), é definido como o conjunto de informações internas e/ou externas coletadas e processadas com objetivo de serem analisadas e, eventualmente, implantadas, resultando numa decisão de investimento.

\subsection{Riscos acautelados nas decisões de financiamento de projetos de investimento}

A utilização sobre os fundos mutuados pelo Banco está sujeita a diversos riscos de caráter sistemático, operacional e financeiro que urge identificar previamente. Segundo Tavares, Pacheco e Pires (2016) e Tavares, Pacheco e Almeida (2015), os riscos traduzem-se num determinado grau de incerteza associado à desejada capacidade de serviço da dívida da Empresa. Portanto, o analista deve procurar caracterizar o melhor possívelos riscos, o que lhe permitirá igualmente definir qual o tipo de controlo mais adequado ao acompanhamento dos créditos.

Os principais riscos que podem ser identificados no âmbito de qualquer análise de crédito empresarial são os seguintes: 


\section{pontěditora}

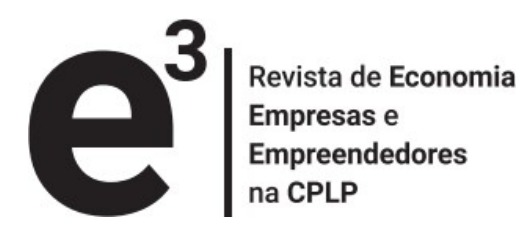

- Riscos macroeconómicos - caracterizado pelas políticas governamentais de caráter orçamental que podem afetar o poder de compra e a localização das unidades empresariais, o incentivo ao investimento, o impacto nas relações laborais e a cooperação internacional; a inflação que tem efeitos na competitividade a nível interno e internacional; a política cambial pela volatilidade e efeitos nas importações e exportações; a política do ambiente, com efeitos na comercialização dos produtos e custos não reprodutivos; assim como o risco do país pela convertibilidade cambial e embargos comerciais;

- Riscos setoriais - relacionados com o nível de maturidade e efeitos nas margens, desequilíbrio entre a oferta e a procura, barreiras à entrada de mercadorias do exterior, barreiras tecnológicas, políticas governamentais a nível setorial, protecionismo e o surgimento de produtos substitutos;

- Riscos de empresas - relacionado com o ciclo de conversão de ativos e a sua dinâmica; eventuais disfunções nos recursos humanos, características das instalações imobiliárias e dos equipamentos (e.g., contrato, estado de conservação, etc.); posição concorrencial no nível dos produtos e mercados, quotas e rivalidade; políticas de preços e estruturas de custos;

- Riscos de gestão - composição dos corpos sociais (idade, mandatos, equilíbrios de forças); experiência e historial de sucesso (espírito de inovação e capacidade reativa); relações entre o Banco e a gestão, níveis de sistemas de informação; níveis de definição estratégica e de objetivos; nível de motivação.

O Banco Nacional de Angola (BNA), enquanto autoridade de supervisão bancária do país, tem permanecido atento ao desenvolvimento do setor financeiro bancário e aos níveis de riscos incorporados, emitindo normativos que visam a implementação em Angola das melhores práticas internacionais do setor bancário. Um desses normativos é, precisamente, o Aviso n. ${ }^{\circ}$ 2/2013, que impõe às instituições bancárias o estabelecimento de um sistema de gestão do risco que incorpore um conjunto integrado de políticas substanciado em procedimentos, limites, controlos e sistemas, com vista ao desenvolvimento de técnicas de análise de riscos mais adequadas para o estádio cada vez mais avançado de desenvolvimento do sistema financeiro angolano.

Os normativos do BNA representam grandes desafios para as instituições financeiras.

$\mathrm{e}^{3}$ - Revista de Economia, Empresas e Empreendedores na CPLP | Volume 4 | Número 1 


\section{pontěditora}

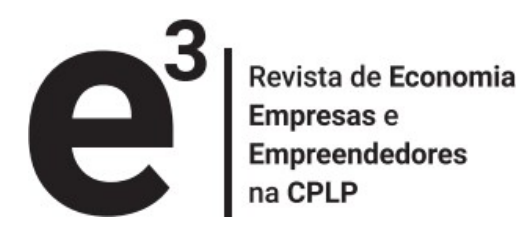

Esses normativos estão associados aos Acordos de Basileia, particularmente o segundo acordo (Basileia II), que define um conjunto de melhores práticas no desenvolvimento e utilização de técnicas de análise do risco de crédito, além dos processos de concessão, acompanhamento e recuperação de crédito.

Uma análise importante sobre o risco de crédito no setor bancário angolano é apresentada por KPMG (2013). Nesse relatório refere-se que o setor bancário angolano tem vindo a dar claros sinais de expansão, verificando-se assim um esforço assinalável por parte das instituições bancárias que procuram estar presentes em todas as Províncias, inclusivamente nas diferentes localidades. Essa expansão representa uma ousadia dos bancos, que procuram acompanhar o desenvolvimento da economia em geral. Porém, olhando para o agravamento do nível de crédito malparado que se verifica no setor, essa expansão pode implicar um relaxamento dos processos de avaliação de créditos por parte dos bancos e, por isso mesmo, um aumento da assunção do risco de crédito por parte da banca angolana.

\subsection{As técnicas de análise de risco dos projetos de investimento}

De acordo com a KPMG (2013), as técnicas de análise de risco podem ser genericamente divididas em modelos de rating e de scoring. Os modelos de rating são voltados para segmentos de Empresas e têm como suporte as demonstrações financeiras utilizadas com frequência (balanço, demonstração de resultados, orçamentos, etc.), das quais podem ser extraídos simples indicadores relacionados com a liquidez, solvabilidade, grau de endividamento, de autonomia financeira, etc. O modelo de rating pode ainda ser dividido em dois: modelos aplicacionais, "utilizados no âmbito da concessão de operações de crédito" e modelos comportamentais, "utilizados ao longo da vida do crédito". Estes são os modelos de PD (Probability of Default ou probabilidade de incumprimento), uma vez que o objetivo é a determinação da probabilidade de uma operação ou cliente entrar em incumprimento. Para os créditos que já se encontrem em incumprimento são utilizados modelos que permitem estimar as perdas associados a estas operações, geralmente denominados modelos de LGD (Loss Given Default ou perda em caso de incumprimento).

O modelo de scoring é, fundamentalmente, aplicável ao crédito a particulares e visa a análise objetiva do risco, procurando avaliar a capacidade e solvabilidade do cliente.

$\mathrm{e}^{3}$ - Revista de Economia, Empresas e Empreendedores na CPLP | Volume 4 | Número 1 


\section{pontěditora}

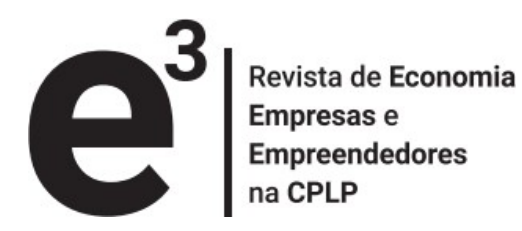

Estes modelos obedecem às mesmas regras que a avaliação de risco das empresas. É necessário conhecer a finalidade do crédito, o montante do crédito a conceder, o prazo de reembolso, a capacidade de reembolso do cliente. Este método de avaliação apresenta alguns factores negativos face à situação atual dos Bancos: é um procedimento moroso, não garante homogeneidade da decisão e está sujeito a variações de humor dos decisores, para além de uma forte componente subjetiva. Porém, o scoring é um método extremamente simples e usado sem recurso a tecnologias avançadas, nomeadamente com uma tabela de pontuação, que poderá ser utilizada por qualquer gestor de cliente.

A massificação da atividade bancária no domínio do crédito a particulares impõe que o Banco desenvolva ou adquira um aplicativo com rotinas de scoring automatizado para permitir o registo de um conjunto de factores de avaliação sobre o cliente e verificar se a pontuação final permite a aprovação da operação ou se a rejeita. Acreditamos que o sistema de scoring poderá tornar-se essencial num panorama de massificação da atividade bancária, sendo de utilização extremamente simples, não necessitando de conhecimentos específicos de qualquer tipo, somente tornando-se necessária a intervenção de um especialista de análise de risco, caso o sistema não aprove a operação e se pretenda uma reanálise pelo processo tradicional. Assim, o Banco poderá construir um sistema de scoring que reproduzirá a sua própria cultura e filosofia no domínio da concessão de crédito.

\subsection{Problema e perguntas de investigação}

Como referido anteriormente, o objetivo deste trabalho é realizar um estudo sobre as ferramentas e técnicas que o Banco de Poupança e Crédito aplica na análise e avaliação de projetos de investimento dos seus mutuários, mediante a comparação dos seus processos com os apresentados na literatura, com vista a uma melhor forma de lidar com o risco de crédito e a problemática do crédito mal parado.

O elevado nível de créditos mal parados verificados na banca angolana, em geral, e no Banco de Poupança e Crédito, em particular, indicia uma insuficiência ou deficiência das ferramentas e técnicas de análise e avaliação de projetos de investimento que o BPC utiliza atualmente, traduzida numa inadequação ao risco de crédito que o banco vem incorrendo nos últimos anos.

$\mathrm{e}^{3}$ - Revista de Economia, Empresas e Empreendedores na CPLP | Volume 4 | Número 1 


\section{pontěditora}

Diante da realidade apresentada da economia e da banca angolana, levantam-se as seguintes perguntas de investigação:

- Como se desenvolve o processo de análise e avaliação de projetos de investimento no BPC?

- Que ferramentas e técnicas são utilizadas no processo de análise e avaliação de projetos de investimento do BPC?

- Que riscos são normalmente acautelados e que medidas são adotadas para mitigar esses riscos na seleção de pedidos de crédito ou financiamento bancário para fins de investimento?

- De entre as inúmeras ferramentas e técnicas de análise e avaliação de projetos de investimento apresentadas na literatura científica, quais podem ser melhor adaptadas à situação ou realidade concreta do BPC?

\section{Apresentação e discussão do estudo de caso}

\subsection{Princípios subjacentes à avaliação de projetos de investimento desenvolvida pelo BPC}

De acordo com o regulamento geral de crédito do Banco de Poupança e Crédito (BPC, 2014a), os princípios e regras gerais, que orientam o processo de análise e avaliação de projetos de investimento e de créditos em geral, obedecem às orientações ou requisitos definidos pelo Banco Nacional de Angola (BNA), bem como pela política de risco de crédito definida pelo Comité de Crédito e pelo Conselho de Administração do Banco, alinhada com os seus objetivos estratégicos e pelos limites de concentração fixados ou a fixar e pelos restantes normativos internos associados à atividade do Banco.

Assim, para a análise e avaliação de projetos de investimento, o BPC observa os seguintes princípios:

- Princípio da capacidade de endividamento e idoneidade do proponente do investimento;

- Princípio da avaliação de risco; 


\section{pontěditora}

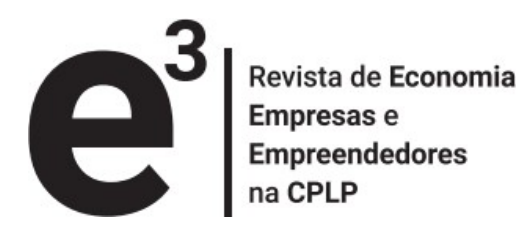

- Princípio da responsabilidade de gestão;

- Princípio do acompanhamento e recuperação de crédito;

- Princípio da concentração e diversificação da carteira de investimento.

O princípio da capacidade de endividamento e idoneidade do proponente do investimento recai sobre o seu comportamento, a situação conjuntural do setor de atividade em que se insere, a adequação da operação, prazos propostos, condições financeiras e demais condições, bem como a sua solidez financeira e capacidade de reembolso, incluindo, ainda, as garantias e colaterais exigidas pelo Banco.

O princípio da avaliação de risco tem por base a classificação do risco do proponente do projeto, de acordo com o segmento em que se insiram e os modelos de avaliação de risco que são desenvolvidos pela Direção de Risco Global. Um outro princípio subjacente à análise e avaliação de projetos de investimento no BPC é o princípio da rendibilidade associada ao risco, que leva em conta, entre outros, as condições financeiras associadas às operações de crédito ou financiamento em questão, o nível de provisionamento associado ao perfil de risco do cliente e suas operações e a identificação do nível de concentração das operações de crédito ou financiamento, face ao total de exposição de crédito do Banco e face à capacidade financeira de cada cliente. O princípio da responsabilidade de gestão substancia-se na intenção do BPC em fazer corresponder apenas um responsável pelo acompanhamento comercial do proponente de um projeto de investimento (seja um cliente individual ou um grupo económico), de forma a assegurar uma plenitude e consistência na identificação e análise das exposições e responsabilidades de crédito de forma agregada, possibilitando um maior rigor na análise e determinação do órgão e o escalão de apreciação e decisão das respetivas propostas de crédito.

Por fim, o princípio do acompanhamento e recuperação de crédito visa o desenvolvimento de procedimentos de acompanhamento das operações de crédito com o objetivo de deteção antecipada de sinais de deterioração das condições creditícias dos clientes, ao passo que o princípio da concentração e diversificação da carteira de investimento visa evitar a existência de uma concentração excessiva da carteira de crédito, seja sobre uma mesma entidade individual, grupo económico ou setor de atividade.

$\mathrm{e}^{3}$ - Revista de Economia, Empresas e Empreendedores na CPLP | Volume 4 | Número 1 


\section{pontěditora}

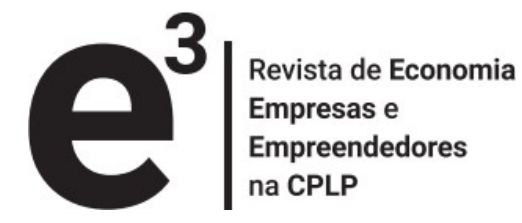

O Regulamento Geral de Crédito do Banco de Poupança e Crédito (BPC, 2014a) fornece inputs que permitem aferir o processo de análise e avaliação de projetos de investimento desenvolvido pelo BPC. Este processo enceta com uma proposta de financiamento que o proponente remete a um determinado balcão do banco, que é dirigido à área de Análise de Crédito, permitindo uma adequada e consciente tomada de decisão. O processo de análise é ainda complementado com o parecer da Direção de Risco Global, para as operações que pelo montante envolvido ou o grau de complexidade da operação assim o justifiquem, nomeadamente para as operações que são decididas ao nível do Comité de Crédito.

De acordo com o mesmo regulamento geral, na origem de crédito o relacionamento creditício com o cliente ou grupo económico deve ser efetuado preferencialmente através das agências, dependências, balcões, centros de empresas e centros de negócios do banco de opção, pelo que todo e qualquer pedido de crédito deverá ser apresentado através do gestor responsável pelo acompanhamento do cliente, sendo que excecionalmente os mesmos processos poderão ser encaminhados diretamente para as respetivas direções comerciais.

A área comercial articula com o cliente as condições para atribuição de uma linha de crédito/limite, ou de uma operação pontual, tendo em conta os preceitos constantes no regulamento geral de crédito, fichas de produtos ou respetivas normas de enquadramento, para apreciação e concretização.

Em todas as propostas de crédito é requerido o preenchimento e entrega de uma carta de solicitação, devidamente fundamentada através da indicação dos seguintes elementos: finalidade, montante, prazo, condições e preçários, modalidade, plano de reembolso, suficiência e liquidez das garantias e colaterais, rendibilidade do cliente e/ou grupo económico referente ao ano anterior, fonte de rendimento e capacidade de reembolso do empréstimo, tempo e tipo de relacionamento com o Banco. A carta de solicitação de crédito deverá ser acompanhada de toda a documentação que permita fundamentar a operação e conhecer a qualidade creditícia dos mutuários, assim como uma adequada e consciente tomada de decisão.

Na documentação para a concessão de crédito às empresas deverá ser apresentada com a carta-pedido a devida documentação certificada legalmente e/ou auditada e atualizada. Após ter-se dado entrada de toda a documentação exigida, segue todo um processo de 


\section{pontěditora}

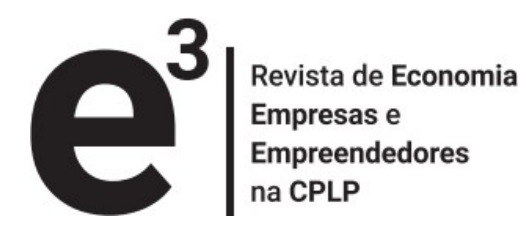

análise documental ou análise do próprio crédito, conforme descrito abaixo.

O Banco deve considerar, por regra, como situações inibidoras da concessão de crédito, os clientes que apresentem as seguintes situações: a não apresentação da documentação exigida ou ausência de atualização da mesma sempre que necessário e solicitado pelo Banco; crédito vencido no Banco ou no sistema bancário; sinais de alerta moderados, grave ou muito grave; dívidas ao Fisco e à Segurança Social e situação de incumprimento; processos judiciais e situações litigiosas, com repercussões negativas; irregularidade na movimentação das suas contas ou ocorrência de incidentes, não justificados nos últimos dois anos; desemprego ou incapacidade para gerar os meios necessários e suficientes para cobertura do serviço da dívida; incumprimento das cláusulas e acordos, negociados com o banco ou com sistema bancário.

$\mathrm{Na}$ apreciação de uma proposta de financiamento remetida ao BPC, a análise/avaliação do projeto radica em indicadores económico-financeiros deduzidos a partir das demonstrações financeiras (balanço e demonstração de resultados), caso a empresa já se encontre plenamente operacional. Caso a empresa ainda esteja a ser constituída, é solicitada a apresentação de um plano de negócio que comporte um estudo de viabilidade técnico-económica e financeira do projetos de investimento. Além disso, o BPC faz recurso a outras fontes de informação, designadamente a base de dados da Central de Informação e Risco de Crédito (CIRC), mantida pelo BNA, e listas de devedores ao Fisco e à Segurança Social. Além do recurso às fontes referidas, o processo de análise/avaliação de projetos do BPC também se apoia em modelos de rating/scoring, baseados em informações de natureza quantitativa e qualitativa dos clientes. Para tal, todos os clientes são classificados com um nível de risco determinado de acordo com estes modelos.

O objetivo da análise/avaliação é aferir a viabilidade económico-financeira e comercial da proposta apresentada, tendo em conta o enquadramento do negócio no contexto angolano, em geral, e o da zona geográfica onde se realizará o investimento, em especial. Também são tidas em conta as prioridades do governo e a estratégia comercial do Banco, factores que podem ter impacto na rendibilidade do investimento, no retorno da operação e, consequentemente, na decisão de crédito.

Assim, na análise/avaliação de projetos são tidos em consideração: ( $i$ ) o limite máximo de exposição por cliente ou grupo económico; (ii) o preçário da operação (taxa de juro e 


\section{pontěditora}

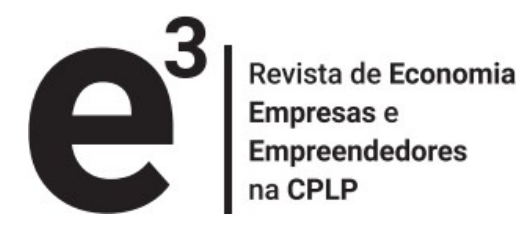

comissões); (iii) a rendibilidade da operação; (iv) as garantias mínimas e colaterais associadas ao crédito; (v) o prazo máximo da operação; o risco subjacente ao projeto; (vi) a capacidade de cumprimento do serviço da dívida por parte do proponente do projeto, medida através da taxa de esforço ou capacidade de endividamento do cliente.

No decorrer do processo, poderá ser agendada e realizada uma visita presencial aos clientes do segmento de Pequenas e Médias Empresas e Corporate com o objetivo de observar "in loco" a atividade do cliente e os objetivos do financiamento solicitado. $\mathrm{Na}$ sequência da mesma, deve ser elaborado um relatório de visita. Esta visita deverá ser assegurada pelas Direções Comerciais (gestor) com a responsabilidade de efetuar a gestão do respetivo cliente (BPC, 2014a).

\subsection{Principais riscos acautelados no processo de análise e avaliação de projetos de investimento do BPC}

O processo de tomada de decisão de financiamento do BPC baseia-se numa análise das características e perfil de cada proponente de projetos de investimento, a tipologia de operação, o nível e tipologia das garantias e colaterais apresentados pelo proponente, bem como as condições contratuais de taxa de juro e prazo associados.

No fundo, o que se quer dizer aqui é que no processo de análise e avaliação de projetos de investimento, desenvolvido pelo BPC, os riscos são acautelados e convenientemente identificados, isto é, consideram-se as origens desses riscos e as suas respetivas dimensões.

Assim, os riscos acautelados pelo BPC relacionam-se ao prazo da operação (curto, médio e longo prazos), ao cliente, à qualidade da gestão e outras características qualitativas, à situação económica e financeira histórica e previsional, ao setor de atividade, experiência no relacionamento com o Banco, existência de incidentes, relacionadas com a segurança do crédito (garantias e colaterais das operações de crédito - todas as garantias e colaterais associados às operações de crédito e os seus efeitos no perfil de risco das operações).

De entre os distintos riscos e origens identificadas acima, os de gestão são seguramente os mais preocupantes para o banco, desde já, pelas muitas dificuldades de gestão que as empresas em Angola apresentam, sobretudo pela insuficiência de competências de gestão empresarial.

$\mathrm{e}^{3}$ - Revista de Economia, Empresas e Empreendedores na CPLP | Volume 4 | Número 1 


\section{pontěditora}

O BPC tem em conta os factores de riscos relacionados com a composição dos corpos sociais, nomeadamente a idade dos gestores, as aptidões e conhecimento do ramo de negócio em que se inserem. Por outro lado, o banco também manifesta preocupação para com a experiência e o historial de sucesso, ou seja, avalia a capacidade de inovação e modernização, a capacidade dos gestores à reação rápida perante os desafios que vão surgindo ao longo do percurso do negócio. Também são tidas em conta as relações entre o banco e os gestores das empresas, concedendo-se financiamento a projetos de investimentos cujos proponente ou gestores gozem de boas relações com o banco, e rejeitando-se para aqueles proponentes cujas relações com o banco sejam más. No caso de empresas já plenamente operacionais, o banco acautela-se contra o nível de organização que essas ostentam em termos de produção de informações úteis, para permitir ao banco acompanhar os exercícios previsionais e controlar os seus orçamentos (vd. Quadro 1).

Quadro 1. Riscos acautelados na análise e avaliação de projetos no BPC

\section{Riscos de gestão}

Composição dos corpos sociais (idoneidade)

Experiência e historial de sucesso (espírito de inovação, capacidade reativa)

Relações entre o banco e a gestão (boas ou más)

Nível dos sistemas de informação de gestão (exercício previsional e controlo orçamental)

Nível de definição da estratégia e de objetivos (clareza e capacidade de prossecução)

Nível motivacional (tipo de comunicação interna, planeamento de carreiras, incentivos)

Fonte: BPC (2014a).

Do mesmo modo, e conforme se pode observar no Quadro 1, o Banco procura acautelar-se face a riscos que se prendem com o nível de definição de estratégias e de objetivos, isto é, se esses são definidos com clareza e exequibilidade. Por fim, há também uma enorme preocupação para com o nível de motivação dos gestores e colaboradores dos projetos, o que poderá perigar o sucesso do desenvolvimento do projeto.

Todos esses riscos são acautelados, visando-se colmatar outros riscos que podem surgir

$\mathrm{e}^{3}$ - Revista de Economia, Empresas e Empreendedores na CPLP | Volume 4 | Número 1 


\section{pontěditora}

após o financiamento (fruto do risco moral), nomeadamente o crédito mal parado, os cheques devolvidos, as ações e execuções judiciais, os pedidos de recuperação ao abrigo de legislação específica e falência.

\subsection{Medidas adotadas para a mitigação dos riscos}

Segundo o Regulamento Geral de Crédito do Banco de Poupança e Crédito (BPC, 2014a), caso o proponente do projeto não tenha meios para fornecer como garantia, o próprio investimento pode servir de garantia. Contudo, para esses casos é necessário haver uma enorme confiança do banco relativamente ao cliente, aferida com base numa série de informações recolhidas a respeito do proponente (históricos de crédito, visitas regulares ao desenvolvimento do projeto, análise da exequibilidade do projeto, etc.).

Para assegurar medidas de contenção ou mitigação de riscos, o BPC exige garantias (aval do Estado, garantia bancária, fiança, livrança e aval) e/ou colaterais (hipoteca, penhor financeiro, penhor mercantil, penhor de equipamento, consignação de rendimentos, leasing, seguro e reserva de propriedade) aceites pelo banco.

Assim, para a mitigação dos riscos inerentes aos processos de análise e avaliação de projetos de investimento submetidos ao BPC, o financiamento só é concedido após a devida formalização de todas as garantias e colaterais que tenham sido considerados na sua aprovação, sendo que no caso de garantias e/ou colaterais cuja formalização careça de um período mais alargado, o desembolso dos fundos associados à operação de crédito deverá ser proporcional à formalização das respetivas garantias e/ou colaterais. Além disso, em relação ao crédito colateralizado por imóveis, a avaliação dos ativos sobre os quais incide cada colateral deverá ser efetuada por peritos independentes e revistas nos termos definidos pela regulamentação do Banco Nacional de Angola.

\subsection{Políticas de gestão de riscos do BPC}

De acordo com Tavares, Pacheco e Pires (2016), em muitos países a gestão do risco tem assumido, cada vez mais, um papel de obrigatoriedade nas empresas, ao ponto de ser considerada uma ferramenta imprescindível, sem a qual se torna mais árduo o funcionamento da empresa. Com o BPC não é diferente. O Banco encontra-se atualmente a desenvolver o projeto "Transformação da Função Risco", que constitui um instrumento de gestão de riscos consubstanciado na adequação da sua gestão de riscos

$\mathrm{e}^{3}$ - Revista de Economia, Empresas e Empreendedores na CPLP | Volume 4 | Número 1 


\section{pontěditora}

às melhores práticas nacionais e internacionais (e.g., Basileia) e dar resposta às novas exigências do mercado, focando em seis grandes pilares de atuação: Governação, Risco de Crédito, Risco Operacional, Riscos Financeiros, Informação de Suporte e Capacitação (BPC, 2014a).

No financiamento aos projetos de investimento e na concessão de crédito em geral, o BPC rege-se pelos Avisos n. ${ }^{\circ}$ 3/12 de 28 de março e n. ${ }^{\circ} 8 / 07$ de 12 de setembro, ambos do Banco Nacional de Angola.

De acordo como relatório e contas de 2014 do Banco (BPC, 2014b), no ano de 2014, no âmbito do projeto de "Transformação da Função Risco", o Banco procedeu à atualização do regulamento geral de crédito, documento consultado neste trabalho. No final desse ano, deu-se início à atualização dos limites de competências para cada nível de decisão, assegurando a intervenção de, no mínimo, dois intervenientes no processo de aprovação das operações de crédito. No âmbito da recuperação de crédito, está em fase de conclusão um sistema de rating para a avaliação do risco de crédito do segmento de empresas.

Atualmente, a gestão dos riscos financeiros no BPC é partilhada pelas Direções de Risco Global, Tesouraria e Mercados e a de Planeamento e Controlo de Gestão, e baseia-se essencialmente na análise de indicadores de liquidez e solvabilidade. Contudo, o projeto de "Transformação da Função Risco" vem reforçar a segregação de funções no âmbito dos riscos financeiros, por via da operacionalização da intervenção da Direção de Risco Global na quantificação, avaliação e controlo destes riscos e da redefinição das responsabilidades de cada uma das áreas intervenientes" (BPC, 2014b).

O BPC produz, atualmente, relatórios periódicos para avaliar e monitorar a exposição aos riscos financeiros, tais como o risco de taxa de juro, de taxa de câmbio e de liquidez, por faixas de prazo residual dos ativos e passivos. Para o efeito, deu-se início ao desenvolvimento de uma ferramenta voltada à gestão de ativos e passivos, cuja implementação previa-se efetivar em 2015. Quanto ao risco cambial, o BPC centraliza a sua atuação dentro dos limites estabelecidos pelo Aviso n. ${ }^{\circ}$ 5/2010 do Banco Nacional de Angola.

O acompanhamento e monitorização da posição cambial do banco "são feitos através da análise do Relatório de Exposição Cambial, remetido numa base diária ao Banco Nacional de Angola, que engloba a exposição cambial das posições ativas e passivas nas 


\section{pontěditora}

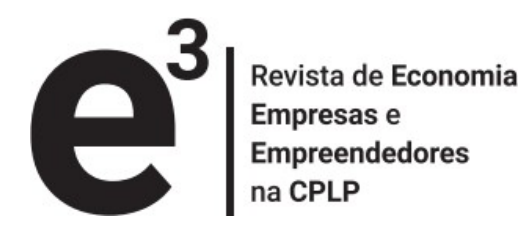

diversas moedas, bem como das rubricas extrapatrimoniais. Em 31 de dezembro de 2014, o BPC registava uma exposição cambial longa, igual a 4,0\% dos Fundos Próprios Regulamentares, dentro do limite de $20 \%$ estabelecido pelo órgão regulador".

A gestão do risco operacional ainda se encontra dispersa em diferentes áreas do BPC, estando, no âmbito do projeto de "Transformação da Função Risco", a ser implementadas ações no sentido de viabilizar a gestão centralizada deste tipo de risco.

Em 2014, foi elaborado um manual de risco operacional que conforma as diretrizes das políticas e princípios gerais da gestão do risco operacional e foi aprovada uma matriz de registo de ocorrências, cuja operacionalização previa-se efetuar no primeiro trimestre de 2015 (BPC, 2014b).

Durante o desenrolar do ano de 2014, foi implementada igualmente a aplicação "Argus Compliance", cujo propósito é o controlo de transações suspeitas de branqueamento de capitais e de financiamento ao terrorismo. Esta é, sem dúvida, uma importante solução, uma vez que os incumprimentos à lei podem implicar sérios problemas e riscos de compliance.

\subsection{Composição da carteira de clientes do BPC}

O BPC atua em quatro áreas de negócio diferenciadas, nomeadamente, o Corporate, Pequenas e Médias Empresas, Particulares e Micro-Finanças. O segmento Corporate, que merece esclarecimento aqui, inclui as grandes empresas públicas e privadas e os organismos e instituições do Estado. O Gráfico 1 revela que do total da sua carteira de clientes Corporate, $90 \%$ são do setor privado, contra $10 \%$ do setor público, o que mostra claramente o compromisso do Banco para com o cumprimento da sua missão em contribuir para o desenvolvimento económico do país, promover a criação de emprego em parceria com o fomento da atividade empresarial e melhorar o bem-estar da população. 


\section{pontěditora}

Gráfico 1. Composição da Carteira de Crédito por Tipo de Cliente (\% do volume)

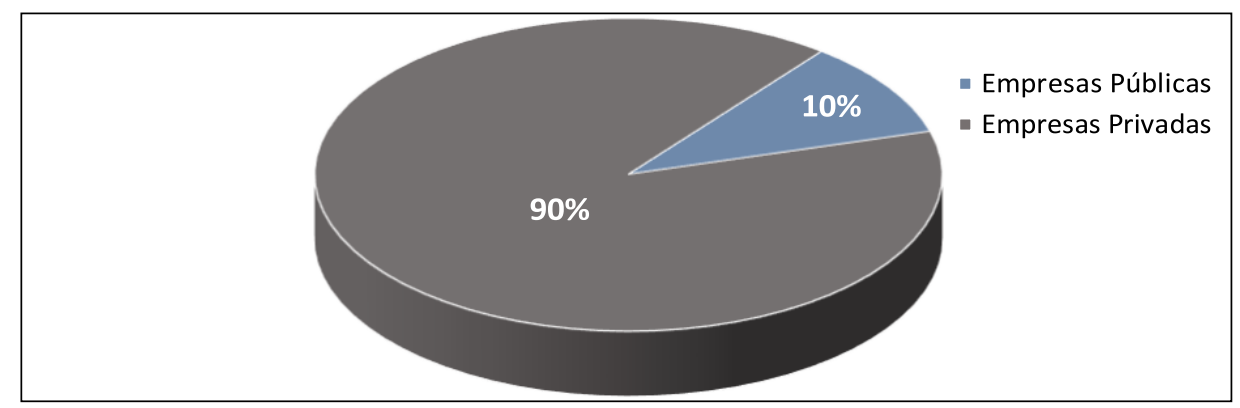

Fonte: Adaptado de BPC (2014b).

Segundo o relatório do BPC que está aqui a ser analisado, verificou-se uma ligeira contração no processo de dação de crédito às Pequenas e Médias Empresas, o que se deve à estratégia de recuperação de operações com elevada antiguidade, cujo peso deste segmento sobre o crédito vencido correspondeu a 46,7\%, contrariamente aos Particulares que, com a maior absorção dos empréstimos, se apresentam com um grau de incumprimento equivalente a 7,3\%, denotando menor risco.

\subsection{Créditos e depósitos do BPC}

O Gráfico 2 demonstra um crescimento do nível de créditos concedidos (cerca de $38,50 \%$ ) e dos depósitos captados (cerca de 64\%) entre 2012 e 2014. No ano de 2014, o Banco de Poupança e Crédito concedeu, aos vários setores da economia, créditos que resultaram no saldo bruto final de 917,5 mil milhões de Kwanzas, equivalentes a 8,9 mil milhões de Dólares Americanos, o que correspondeu a um aumento de 243,8 mil milhões de Kwanzas (36,2\%) em comparação com o ano anterior. Refira-se que, 50,9\% do crédito foi destinado a particulares e 31,7 às grandes empresas. 
Gráfico 2. Depósitos vs. Créditos: 2012, 2013 e 2014

(valores em milhares de milhões de Kwanzas)

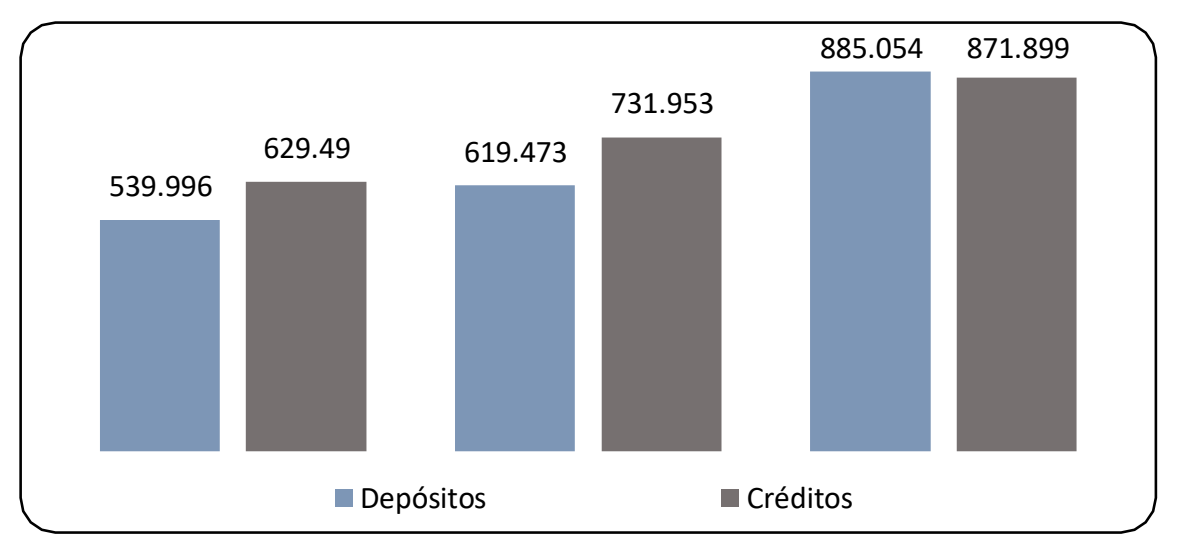

Fonte: Adaptado de BPC (2014b).

Observando o Gráfico 3, pode-se notar que o rácio de transformação dos depósitos em créditos do banco registou um aumento, passando de 96\% em dezembro de 2012 para 92,00\% em dezembro de 2013 e para 105,20\% em dezembro 2014, pesando sobre si a reestruturação de créditos vencidos e não pagos. O banco registou insuficiências de liquidez de forma continuada, o que dificultou de sobremaneira a gestão dos fundos, levando ao recurso aos mercados internacionais e ao mercado interbancário, para manter a sua força catalisadora no desenvolvimento da economia nacional.

Gráfico 3. Rácio de Transformação: 2012, 2013 e 2014

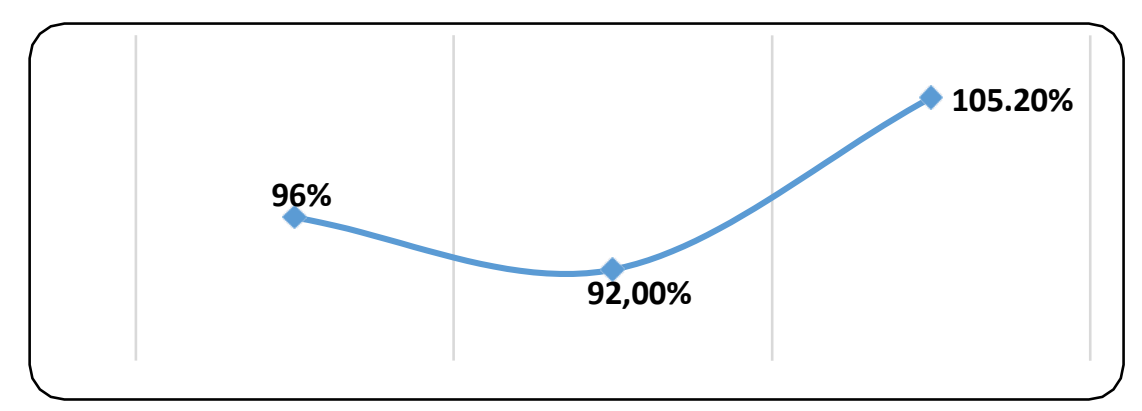

Fonte: Adaptado de BPC (2014b).

A situação acima descrita implicou uma situação de risco das operações de crédito, que se agudizou com os atrasos no cumprimento do serviço da dívida dos seus clientes. $\mathrm{O}$ nível dos riscos inerentes a esses atrasos é revisto mensalmente em função do tempo decorrido desde a data de entrada das operações em incumprimento, calculando-se as 


\section{pontěditora}

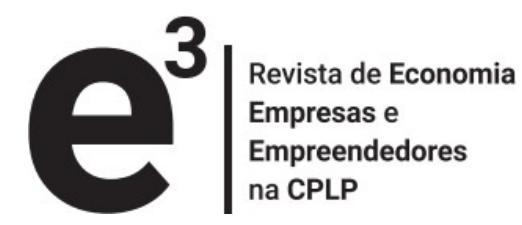

devidas provisões, conforme abaixo descrito.

\subsection{As provisões para créditos de liquidação duvidosa do BPC}

De acordo com o BPC, a 31 de dezembro de 2014, a dívida dos 20 maiores devedores totalizava 245,2 mil milhões de Kwanzas, ou seja, 26,8\% da carteira de crédito e 249,0\% dos Fundos Próprios Regulamentares, contra 29,4\% e 219,2\%, respetivamente, em 2013, demonstrando, por um lado, uma melhoria do grau de concentração, mas, por outro lado, uma degradação do nível de exposição

Os níveis de Créditos e Juros Vencidos ascenderam a 188,2 mil milhões de Kwanzas em 2014, contra 118,8 mil milhões de Kwanzas em 2013. Esse agravamento deveu-se fundamentalmente aos atrasos nos pagamentos de empresas com direitos de crédito sobre o Estado. Como corolário desse problema, o rácio do crédito vencido registou uma degradação, passando de $17,6 \%$ para $20,5 \%$.

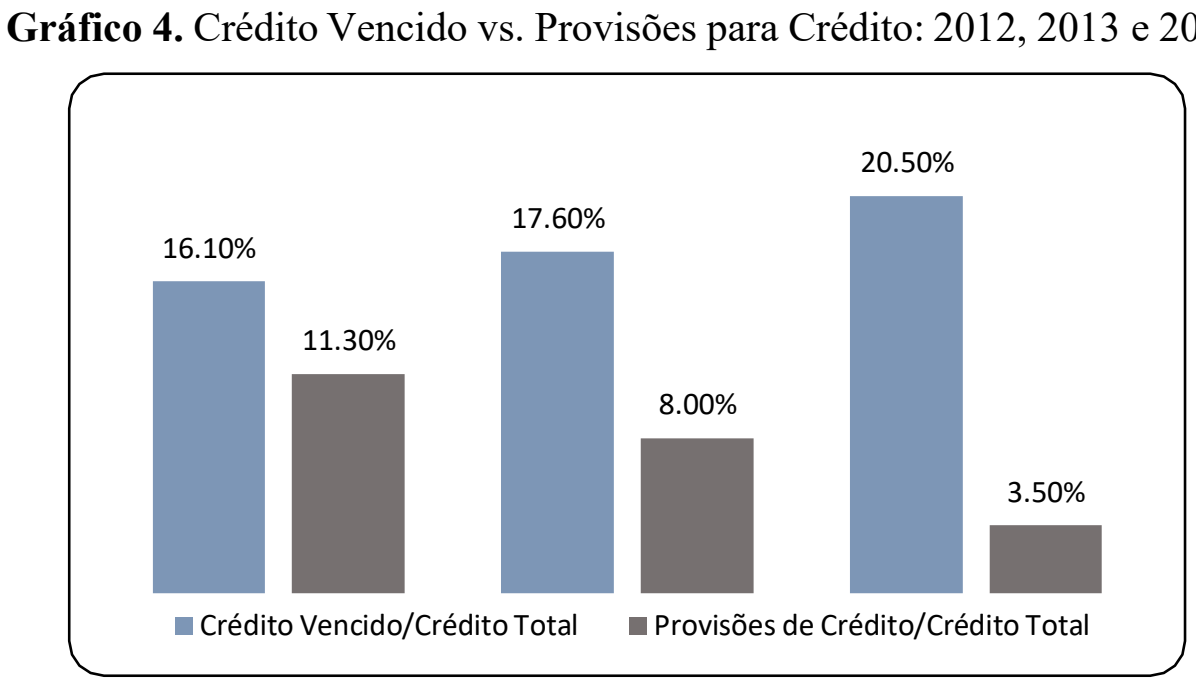

Fonte: Adaptado de BPC (2014b).

Nas operações de financiamento de projetos de investimento e de crédito, em geral, os bancos são forçados (a par das garantias e avales prestados) a constituir provisões, de acordo com o Aviso n. ${ }^{\circ}$ 3/2012, de 28 de março, que veio revogar o Aviso n. ${ }^{\circ} 4 / 2011$, de 8 de junho, do BNA sobre a metodologia de classificação do crédito concedido a clientes e a determinação das respetivas provisões. Ora, o agravamento do crédito vencido, deveria inspirar uma maior reserva de contingência, isto é, um nível maior de 


\section{pontěditora}

provisões para cobranças duvidosas, o que não ocorreu, pois, como demonstra o gráfico acima, o banco foi diminuindo cada vez mais as provisões, de 11,10\% em 2012 para $8,00 \%$ em 2013 e 3,50\% em 2014.

Finalmente, quando se analisa a estrutura do crédito vencido por tipo de cliente, constata-se um agravamento no grau de cobrabilidade das empresas, passando de $22,7 \%$ para $32,2 \%$ o rácio de crédito vencido, a despeito de uma melhoria do rácio pertencente aos particulares para $3,5 \%$, contra os $8,9 \%$ do ano anterior.

\subsection{Crédito mal parado e avaliação de riscos de crédito no BPC}

Apesar dos riscos contra os quais o BPC procura acautelar-se, a verdade é que o Banco enfrenta graves problemas, traduzidos na qualidade dos créditos ou financiamento aos projetos que tem procurado abraçar. O nível de créditos mal parados tem crescido nos últimos anos e o Ministério das Finanças angolano já deu orientações para examinar essa questão na perspetiva de separar os ativos recuperáveis dos maus ativos que ainda figuram na carteira de crédito da instituição. No fundo quer-se verificar o que é e o que não é cobrável, com vista a desenvolver-se um processo do saneamento da carteira de créditos do BPC.

De acordo com informação pública veiculada, tanto pela imprensa nacional quanto pelos relatórios e contas da própria instituição, o BPC debate-se com um grave problema de provisões inadequadas face ao nível de créditos mal parados que degrada a sua carteira de créditos. Note-se que, o rácio de créditos mal parados do BPC, em especial a particulares, que constituem $95 \%$ dos seus clientes, subiu de 17 para $23 \%$ entre 2013 e o terceiro trimestre de 2014. Auditores externos que revisaram as contas do Banco de 2014 alegam que as provisões para riscos de crédito (crédito de cobrança duvidosa) não são suficientes para cobrir as perdas estimadas (Expansão, 2015).

As maiores perdas provêm de operações alvo de acordos de reestruturação de dívida de entidades fornecedoras do Estado. Ainda de acordo com essa entidade de auditoria independente, alegadamente por limitações dos seus sistemas informáticos, o Banco não consegue cumprir com os requisitos de provisão exigidos pelo Aviso n. ${ }^{\circ}$ 11/2014 do BNA. O crédito em mora atingiu, no final de 2014, cerca de 79,5 mil milhões de Kwanzas (772,7 milhões de Dólares), o que é, fundamentalmente, um reflexo dos atrasos nos pagamentos do Estado às empresas prestadoras de serviços. Este montante

$\mathrm{e}^{3}$ - Revista de Economia, Empresas e Empreendedores na CPLP | Volume 4 | Número 1 


\section{pontěditora}

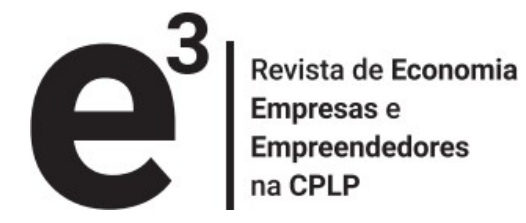

representava um crescimento de $289,7 \%$, em relação a dezembro de 2013, e correspondia a $27,3 \%$ do crédito total do segmento (15,9\% no fím de 2013$)$.

Assim, apesar da apresentação dos resultados dessa pesquisa revelarem que o BPC procura conduzir as suas operações tendo em conta as melhores práticas nacionais e até internacionais, acautelando-se contra os riscos inerentes à sua atividade, a verdade é que os problemas que apresenta revelam claramente problemas na sua gestão de riscos e/ou processos de análise e avaliação de projetos de investimentos.

O BPC continua a expandir a sua rede de balcões em todo o país e, à semelhança do que sucede com todo o sistema financeiro angolano, o Banco apresenta um processo de gestão do risco de crédito altamente centralizado, com as decisões de financiamento da maior parte dos investimentos a serem tomadas em Luanda, a capital do país.

Por ser essencialmente um banco de capitais públicos, o BPC tem sido condescendente em facilitar a concessão de créditos e/ou financiamento a projetos de investimento de uma forma mais elementar, descorando o rigor que se exige às instituições financeiras. Isto conduziu, até 2014, a que tenham sido concedidos créditos a entidades que nunca chegaram a honrar com o serviço da dívida, alegadamente porque os negócios falharam ou porque se registaram situações totalmente imprevistas.

De acordo com o Novo Jornal (2013), “o perfil dos clientes do BPC, maioritariamente funcionários públicos, e a sua composição acionista, são fatores apontados como responsáveis pelo aumento do crédito mal parado no banco público". A mesma fonte refere que o banco continua a ter dificuldades em recuperar o dinheiro emprestado, pois muitos dos beneficiários são funcionários públicos que, apesar de não terem os salários em atraso, depois de receberem o crédito mudam de banco, o que dificulta a recuperação do mesmo. Também é referida outra situação relacionada com o apoio ao empresariado nacional. Muitos empresários têm beneficiado dos créditos e não devolvem o dinheiro. Questionado se o banco não pede garantias a quem empresta, a mesma fonte esclareceu: "Para os funcionários públicos a garantia é o próprio salário destes, mas para os empresários e outros a garantia quase que não existia, porque o objetivo era potenciar os empresários angolanos. Mas, infelizmente muitos não souberam aplicar o dinheiro recebido e estão com dificuldades em restituir o capital recebido". Mesmo não avançando os montantes em causa, a fonte assumiu que a situação tem criado dificuldades de liquidez no banco e obrigou o Presidente da

$\mathrm{e}^{3}$ - Revista de Economia, Empresas e Empreendedores na CPLP | Volume 4 | Número 1 


\section{pontěditora}

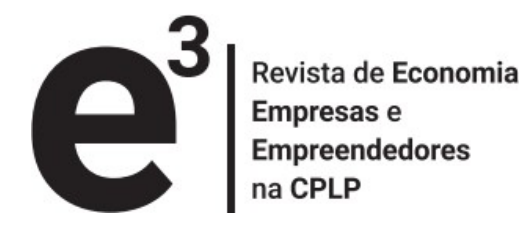

República a criar uma comissão multissetorial para avaliar o real estado financeiro do BPC, entretanto aconselhado a não fazer novas operações.

De acordo com uma outra fonte jornalística (Jornal de Angola, 2014), o presidente do conselho de administração do banco, Paixão Júnior, alega ser provável que uma pequena parte das dívidas ao BCP seja incobrável, porém, defende que a maioria dos créditos são recuperáveis porque as empresas, cujos projetos de investimento o banco financiou, existem e estão operacionais, e que as mais problemáticas, pelo menos possuem património e, quando o banco executar esse património vai poder reduzir parte do crédito mal parado.

É importante não descurar que o problema do crédito mal parado em Angola é transversal à toda banca, pelo que não deve ser visto como um problema exclusivo do BPC e, como corolário disso, também não deve ser encarado como um problema unicamente relacionado com o controlo interno do BPC, de modo particular, e do seu processo de análise e avaliação de projetos, de modo particular.Assim, observando o Gráfico 5, relativo ao rácio de crédito vencido, conforme avançado no Relatório e Contas do BNA de 2014, há um agravamento do mesmo entre 2012 e 2014.

Gráfico 5. Nível de créditos vencidos na banca angolana: 2012, 2013 e 2014

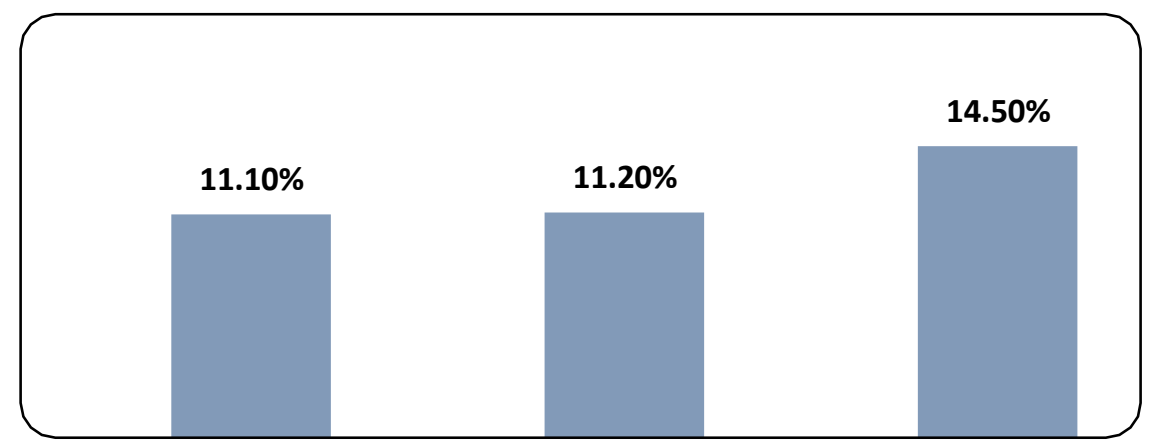

Fonte: Relatório e Contas (2014b).

Por fim, importa salientar que, o Banco visava apostar, entre outras, na melhoria dos mecanismos de gestão de riscos e de controlo interno, no desenvolvimento das competências dos recursos humanos e na promoção da educação e inclusão financeira.

\section{Conclusão}

Após a realização deste trabalho foi possível chegar a importantes conclusões, a respeito

$\mathrm{e}^{3}$ - Revista de Economia, Empresas e Empreendedores na CPLP | Volume 4 | Número 1 


\section{pontěditora}

da dificuldade que o mesmo oferece, uma vez tratar-se de um assunto muito sensível. Para se ter uma ideia, foi muito difícil apurar o que realmente se passa no Banco para explicar os problemas de crédito mal parado. Para um observador independente, esses problemas podem ser decorrentes de eventuais deficiências do processo de análise e gestão de risco do Banco ou em função da própria conjuntura da situação da banca angolana.

Um problema importante verificado neste trabalho é que, pelo facto de tratar-se de um Banco público, o BPC muitas vezes vê-se forçado a apoiar projetos que de outra forma não seriam aceites. Muitos desses projetos não reúnem as condições necessárias para a sua aprovação, mas uma vez tratando-se de projetos ligados a iniciativas do Estado Angolano, o BPC é chamado a apoiar os mesmos.

Por outro lado, ficou claro aqui que a maioria do problema do crédito mal parado com que o Banco se debate provém de clientes alavancados por serviços prestados ao Estado. $\mathrm{Na}$ altura da aprovação desses projetos de investimento os mesmos pareciam reunir as condições para a sua aprovação, porém, com as dificuldades do Estado em pagar a essas entidades, as mesmas acabaram por se ver incapazes de honrar com o serviço da dívida. Este problema revela duas questões: a primeira é decorrente da própria conjuntura económica do país, pois, com a crise, muitos dos fornecedores de bens/serviços ao Estado vêem-se a braços com sérias dificuldades financeiras, até mesmo para se manterem operacionalmente, e ainda mais para honrar o serviço da dívida para com o BPC; a segunda questão, que se pode depreender dessa problemática, é que o Banco terá descurado os riscos que corria ao financiar parte desses projetos, o que indiciaa problemas no seu processo de análise e avaliação de projetos de investimento.

Para o agravamento do crédito mal parado terá contribuído a própria situação económica de Angola. Porém, os processos de análise e avaliação de projetos do BPC apresentam fragilidades em determinados aspetos. Por exemplo, o Banco muitas vezes não exige as devidas garantias reais ou a aplicação de seguros de crédito, exigências que normalmente dariam ao banco a possibilidade de recuperar parte significativa dos créditos vencidos ou mal parados.

Portanto, o problema dos créditos mal parados do BPC estará ligado à conjuntura de crise económica e financeira do país, mas também a problemas ligados com o processo de análise e avaliação de projetos de investimentos que vinham sendo submetidos aos 


\section{pontěditora}

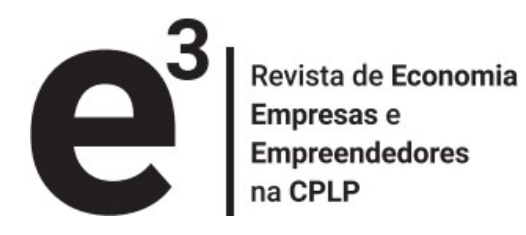

seus diferentes balcões de atendimento nas diversas regiões do país.

No fundo, o problema do banco identifica-se com os decorrentes da informação assimétrica, nomeadamente: a seleção adversa e o risco moral. O Banco precisa de melhorar a forma como seleciona os projetos de investimento que financia. É preciso tornar mais transparente e rigoroso o processo, não só de análise e avaliação de projetos, mas, sobretudo, o de seleção ou aprovação.

Por outro lado, o BPC tem de preparar as condições necessárias para resolver o problema de risco moral dos seus clientes. Para tal, o Banco tem de exigir garantias reais para poder recuperar parte significativa do crédito vencido ou mal parado. Posto isso, importa realçar que o processo de análise e avaliação de projetos de investimento do BPC não ficam aquém das boas práticas nacionais e internacionais, estando o problema ligado à especificidade ou caráter do próprio banco.

Enquanto o banco subjazer refém da situação acima descrita, os problemas vão continuar, por mais perfeito que seja o seu processo de análise e avaliação de projetos. Logo, os problemas do Banco estão mais ligados a condicionalismos impostos pelo Estado e também pelo pouco cuidado na seleção dos projetos aprovados. Em função disso, o Banco praticamente congelou o fluxo de créditos que vinha concedendo até 2014, com a vista a reestruturar a sua atuação em termos de tentativas de recuperação de créditos mal parados, com processos judiciais em curso, conforme avançados por fontes junto da instituição.

Por fim, importa salientar que, relativamente às perguntas científicas identificadas neste trabalho, pode-se concluir que o processo de análise e avaliação de projetos de investimento no BPC é desenvolvido no âmbito de procedimentos regulares, semelhantes ao que sucede com outros bancos nacionais e internacionais.

Não obstante o próprio sistema financeiro angolano ver-se neste momento a braços com sérias dificuldades de mitigação de riscos, e o Banco procurar acautelar-se contra os riscos inerentes ao processo de seleção e atribuição de crédito, pode-se concluir que os elevados níveis de crédito mal parado são um sinal de problemas ao nível do controlo interno do Banco. Porém, este problema afigura-se como um assunto bastante delicado, que só pode ser resolvido mediante uma auditoria ou avaliação do sistema de controlo interno do Banco.

Assim, pode-se depreender aqui que os objetivos deste trabalho foram atingidos até

$\mathrm{e}^{3}$ - Revista de Economia, Empresas e Empreendedores na CPLP | Volume 4 | Número 1 


\section{pontěditora}

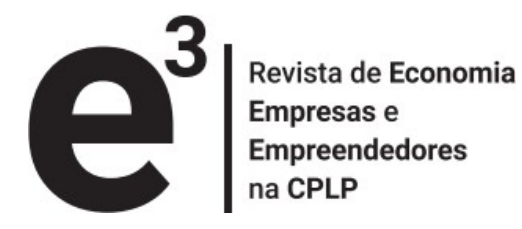

certa medida, dadas as dificuldades de obtenção de dados delicados, relacionados com os procedimentos pouco claros de concessão de créditos no banco em análise. $\mathrm{Na}$ medida em que, o núcleo dos problemas de crédito mal parado do $\mathrm{BPC}$ reside no controlo interno, numa lógica de desenvolvimento de trabalhos futuros, seria interessante a realização de uma investigação relacionada com a avaliação daquele sistema do Banco, com a vista à procura e correção das suas falhas.

\section{Referências bibliográficas}

- Albino, F., Tavares, F. \& Pacheco, L. (2016). "Investimento Direto Estrangeiro em Angola”. Portuguese Journal of Finance, Management and Accounting. 2(3), pp. 3-34.

- Barros, C. P. (2007). Avaliação Financeira de Projetos de Investimento. Lisboa: Escolar Editora, Portugal.

- BPC (2011). Relatório e Contas. Banco de Poupança e Crédito. Luanda, Angola.

- BPC (2014a). Regulamento Geral de Crédito. Banco de Poupança e Crédito. Luanda, Angola.

- BPC (2014b). Relatório e Contas. Banco de Poupança e Crédito. Luanda, Angola.

- Expansão (2015). "BPC com provisões insuficientes para crédito malparado", Jornal Expansão. Disponível em: http://expansao.co.ao/artigo/57760/bpc-comprovisoes-insuficientes-para-credito-malparado (maio de 2015).

- Jornal de Angola (2014). "BPC faz o exame a dívidas à banca". Jornal de Angola

em: http://jornaldeangola.sapo.ao/economia/banca/bpc_faz_o_exame_a dividas a anca (22 de abril de 2014).

- KPMG (2013). Análise ao setor Bancário Angolano. Luanda, Disponível: $<$ http://www.kpmg.com/PT/pt/IssuesAndInsights/Documents/bank-ao201 3.pdf $>$ (3 de novembro de 2014).

- Marques, A. (1998). Concepção e análise de projectos de investimento. Lisboa: Edições Sílabo, Portugal.

- Novo Jornal (2013). “Cresce o crédito mal parado - situação inquieta bancos”. 


\section{pontěditora}

Retirado de: https://centralangola7311.files.wordpress.com/2013/11/novo-jornal302-conomia.pdf. (1 de novembro de 2013).

- Patah, L., \& Carvalho, M. (2016). "Sucesso a partir de investimento em metodologias de gestão de projetos". Production, 26(1), pp. 1-16.

- Soares, I., Moreira, J., Pinho, C., \& Couto, J. (2007). Decisões de Investimento Análise Financeira de Projectos. Lisboa: Edições Sílabo.

- Souza, J. S., \& Neto, F. J. (2012). "O impacto da incorporação da inflação na análise de projetos de investimentos". Produção, 22(4), pp. 709-717

- Tavares, F. O., Pacheco, L., \& Pires, M. R. (2016). "Gestão do Risco nas "PME de Excelência" Portuguesas". Revista Tourism \& Management Studies, 12(2), pp. 135-144.

- Tavares, F. O., Pacheco, L., \& Almeida, E. F. (2015). "Financiamento das pequenas e médias empresas: análise às empresas do distrito do Porto em Portugal”. RAUSP - Revista de Administração, 50(2), pp. 254-267.

\section{(cc) EY-NG-SA}

O trabalho $\mathrm{e}^{3}$ - Revista de Economia, Empresas e Empreendedores na CPLP está licenciado com uma Licença Creative Commons - Atribuição-NãoComercial-Compartilha Igual 4.0 Internacional. 